\title{
Dietary fibre and colon cancer: where do we go from here?
}

\author{
Michael Hill \\ Nutrition Research Centre, South Bank University, 103 Borough Road, London SE1 OAA, UK
}

\begin{abstract}
The relationship between intake of dietary fibre and risk of colon cancer has been studied for 30 years and still the data are inconclusive. There are many possible reasons for this outcome, and they include a failure to consider exposure to dietary fibre separately by source, or colon cancers separately by subsite. These potential confounders have been known for at least 20 years. However, the disease is normally considered by epidemiologists as a single entity. More recently, it has become clear that colon cancer can arise via various histological pathways, and by various genetic pathways. There is no reason at all for assuming that risk factors for these possible pathways are the same. There is a need, therefore, for a more detailed approach to the study of diet and colon cancer, with fibre source and cancer subsite, genetic pathway and histological pathway taken into account.
\end{abstract}

Dietary fibre source: Colon cancer subsite: Genetic variations: Histological variations

It was more than 30 years ago when Burkitt (1969) began to promote his hypothesis that colon cancer was caused not by an excess of fat but by a lack of fibre in the diet. This hypothesis was extremely attractive, and generated a great deal of research. Burkitt (1969) proposed a mechanism by which fibre might protect against colon cancer and aspects of this mechanism were validated by Hill \& Fernandez (1990). However, after some early positive results the data generated were disappointing, leading some prominent epidemiologists (for example, see Jensen, 1989) to reject the hypothesis totally.

After a re-evaluation of the literature Hill (1997) concluded that a number of mistakes were being made. The first was that, although Armstrong \& Doll (1975) had shown that fibre from different sources was related differently to bowel cancer risk, a collective value for fibre from all sources was being used in the epidemiological studies. The second was that NSP was being used as the measure of dietary fibre (intake of which was estimated to be $<15 \mathrm{~g} / \mathrm{d}$ ). Although this assay is excellent for food-labelling purposes, it is inappropriate for testing the Burkitt (1969) hypothesis, since Stephen et al. (1983) had shown that a variable, but sometimes considerable, proportion of the starch intake escapes digestion and so reaches the colon where it behaves as dietary fibre. This finding explained an earlier observation that the daily synthesis of bacterial mass in the colon indicated that the amount of carbohydrate reaching the colon was $60-70 \mathrm{~g} / \mathrm{d}$.

Hill (1997) concluded that there was good evidence from the literature that cereal fibre protects against colon cancer. A consensus group (European Cancer Prevention Consensus Panel, 1998) accepted this conclusion, and expanded it to include breast cancer and possibly a wide range of other cancer sites.

Nevertheless, there is still resistance to the concept that dietary fibre protects against colon cancer, and this opposition comes principally from the Boston group of Willett and colleagues (for example, see Fuchs et al. 1999). A feature of their study cohort of nurses was that they all had low intakes of dietary fibre and particularly low intakes of cereal fibre.

However, perhaps the biggest barrier to clarity in the epidemiology is the failure to take account of the complexity of colon carcinogenesis.

\section{Colon cancer complexity}

There are three main aspects to the complexity of colon carcinogenesis that need to be addressed, i.e. subsite, genetics and histology. The three are interrelated with, for example, some of the subsite differences presumably being due to differences in genetics or histogenesis.

Abbreviation: MI, microsatellite-instability.

Corresponding author: Professor M. Hill, fax +442078158101 or +44 1256880416 email michael.hill.ecp@care4free.net or hillmj@ sbu.ac.uk 


\section{Subsite differences}

It has been clear for 20 years that the epidemiology of cancer of the proximal colon differs from that of the distal colon and of the rectum (de Jong et al. 1972; Jensen 1984). Cancers of the proximal colon have a higher excess of female cases, are more likely to be associated with previous gastric or gallbladder surgery, are more likely to follow the microsatellite-instability (MI) genetic pathway and are less likely to have a demonstrable adenoma precursor. Nevertheless, cancers of the proximal colon are rarely segregated for separate analysis in epidemiological studies.

\section{Colo-rectal histogenesis}

The adenoma-carcinoma sequence in the histogenesis of colo-rectal cancers was demonstrated by Morson (1974). This sequence was later renamed the dysplasia-carcinoma sequence (Morson et al. 1983) to bring it in line with discussions of, for example, cervical cancer, since an adenoma in the colon is histologically defined as an area of dysplasia. A mechanism for the dysplasia-carcinoma sequence was proposed by Hill et al. (1978), which took note of the differences in epidemiology between adenomas and carcinomas of the large bowel (Table 1). On this hypothesis the environmental factors that cause the initial dysplasia in previously normal tissue differ from those that cause the clonal expansion in adenoma growth or the factors that cause increasing severity of dysplasia.

This model has been widely tested and shown to be valid. It ought not to be surprising that the factors that cause expression of the consequences of adenomatous polyposis coli gene mutation differ from those causing expression of the range of mutations involved in the progression to cancer. Table 2 lists some of the dietary factors that have been shown by Boutron et al. (1995) Boutron-Ruault et al. (2001) to have different actions at the adenoma formation stage and

Table 1. Differences in epidemiology between colo-rectal adenomas and carcinomas

\begin{tabular}{lll}
\hline Risk factor & Adenomas & Carcinomas \\
\hline Lifetime risk & Approximately $50 \%<5 \%$ \\
Subsite distribution & Relatively uniform & Concentrated distally \\
Gender ratio of cases $(\mathrm{M}: \mathrm{F}) 1.5-2.0$ & $<1.0$ \\
Tromso $v$. Oslo $v$. Liverpool Similar at all ages & $2 \cdot 5$-fold range in risk \\
Iran v. Colombia & Very different risk & Similar risk \\
\hline
\end{tabular}

M, Male; F, female.

Table 2. The effect of various dietary and diet-related factors on the risk of various stages in the adenoma-carcinoma sequence (Data from Boutron et al. 1995, 2001)

\begin{tabular}{|c|c|c|c|}
\hline Risk factor & $\begin{array}{l}\text { Adenoma } \\
\text { formation }\end{array}$ & $\begin{array}{l}\text { Adenoma } \\
\text { growth }\end{array}$ & $\begin{array}{l}\text { Colon } \\
\text { carcinoma }\end{array}$ \\
\hline Tobacco & Increase & No effect & No effect \\
\hline Alcohol & Little effect & Increase & No effect \\
\hline Physical activity & Little effect & Little effect & Decrease \\
\hline High energy intake & Little effect & Little effect & Increase \\
\hline High BMI & Little effect & Increase & Increase \\
\hline Height or weight & No effect & No effect & No effect \\
\hline
\end{tabular}

at the adenoma growth stage or the progression to carcinoma. These data confirm the validity of the model. A consequence is that new adenoma formation cannot be used to predict the ability of a nutrient to protect against colon cancer (Hill, 2002); to do so only increases confusion in the minds of the general public. For this reason, the European Cancer Prevention Consensus Panel has not changed its advice on the value of fruit, vegetables and wholegrain cereals as part of diet pattern to decrease cancer risk (Hill, 2001).

A further consequence of this model is that the risk factors for cancers arising via the adenoma-carcinoma sequence (where adenoma growth is the rate-limiting step) may be different from those that arise in flat adenomas (with no adenoma growth phase). In consequence, the relationship between diet and colon cancer risk might be much clearer if tumours arising via these two alternative histological pathways were segregated.

\section{Colo-rectal cancer genetics}

Although this subject is still in its infancy, it is clear that there are many alternative genetic pathways to colo-rectal cancer. The most widely discussed pathways are the loss of heterozygosity and the MI pathways (Olschwang, 1999). However, there are other pathways, involving, for example, genetic polymorphisms (Little \& Sharp, 2002).

On the loss of heterozygosity pathway the first step is mutation of the adenomatous polyposis coli gene (which is also the gene mutated in familial polyposis patients). This step is followed by an array of mutations including Kras, DCC, P53 and many others. The current paradigm is that the risk of cancer increases as the number of such mutations increases; their order is thought to be irrelevant. This pathway is said to occur in $>80 \%$ of colo-rectal cancers, although there is little information to confirm that this percentage is accurate for all countries (and good reasons to suspect that the percentage may be different in, for example, Africa).

The MI pathway is followed in $>98 \%$ of cases of human non-polyposis colon cancer, and in about $15 \%$ of all human colo-rectal cancers. The proportion following the MI pathway is higher in proximal cases than in distal cases. Since only $15 \%$ of sporadic colon cancer cases follow this pathway, human non-polyposis colon cancer is not a good model to use to study the relationship between diet and colon cancer. However, as many as $15 \%$ of cases of sporadic cancer follow this pathway, and there is no reason to assume that the dietary risk factors are the same for the two pathways. This percentage is enough to cause confusion in epidemiological studies, and to justify segregating tumours arising via the loss of heterozygosity and the MI pathways for separate analysis.

However, in addition to these major pathways, there is growing interest in the role of enzyme polymorphisms. Those involved in folate metabolism may be important in colon cancer but less so in rectal cancer (Little \& Sharp, 2002) and this factor has been related to the important steps in DNA methylation. However, many other enzyme polymorphisms have attracted interest, including $\mathrm{N}$-acetyl transferases, glutathione transferases and various other enzymes involved 
in detoxification pathways. These polymorphisms have been claimed to modulate the effects of diet on cancer risk (Hill, 2000).

There are some data on the distribution of different polymorphisms for a number of these enzymes, but only for Western countries. In consequence, if it were decided that specific diet patterns were a special risk to individuals with a specific pattern of enzyme polymorphisms it would still be necessary to screen the whole population before targeted dietary advice could be given. However, if an individual was worried about aspects of diet, an enzyme polymorph profile could be carried out and the individual could then be reassured or warned. This possibility is still, however, some way in the future.

\section{Conclusions}

When considering the range of possible confounding factors in the study of diet and colon cancer, it is amazing that any statistically significant results have been obtained at all! The positive results probably apply to tumours located in the most common subsite (sigmoid colon), arising via the most common histological pathway (the adenoma-carcinoma sequence) and the most common genetic pathway (the loss of heterozygosity pathway). The relationships would need to be strong with such tumours, in order to overcome the 'diluting' effect of results obtained with tumours with different characteristics.

\section{References}

Armstrong BC \& Doll R (1975) Environmental factors and the incidence and mortality from cancer in different countries with special reference to dietary practice. International Journal of Cancer 15, 617-631.

Boutron MC, Faivre J, Dop MC, Quipourt V \& Senesse P (1995) Tobacco, alcohol and colorectal cancer. A multi-step process. American Journal of Epidemiology 141, 1038-1046.

Boutron-Ruault MC, Senesse P, Meance S, Belghiti C \& Faivre J (2001) Energy intake, body mass index, physical activity and the colorectal adenoma-carcinoma sequence. Nutrition and Cancer 39, 50-57.

Burkitt (1969) Related disease-related cause? Lancet ii, 1229-1231. de Jong U, Day NE, Muir CS, Barclay TH, Bras G, Foster FH, Jussawalla DJ, Ringertz N \& Shanmugaratnam T (1972) The distribution of cancer within the large bowel. International Journal of Cancer 10, 463-477.

European Cancer Prevention Consensus Panel (1998) Consensus statement on cereals, fibre and colorectal and breast cancers. European Journal of Cancer Prevention 7, Suppl. 2, s1-s4.

Fuchs CS, Giovannucci EL, Colditz GA, Hunter DJ, Stampfer MJ, Rosner B, Speizer FE \& Willett WC (1999) Dietary fiber and the risk of colorectal cancer and adenoma in women. New England Journal of Medicine 340, 169-176.

Hill MJ (1997) Cereals, cereal fibre and colorectal cancer risk: a review of the epidemiological literature. European Journal of Cancer Prevention 6, 219-225.

Hill MJ (2000) Molecular and genetic risk markers in colon cancer trials. European Journal of Cancer 36, 1288-1291.

Hill MJ (2001) ECP dietary advice on cancer prevention. European Journal of Cancer Prevention 10, 183-190.

Hill MJ (2002) Vegetables, fruits, fibres and colorectal cancer. European Journal of Cancer Prevention 11, 1-2.

Hill MJ \& Fernandez F (1990) Bacterial metabolism, fiber and colorectal cancer. In Dietary Fiber: Chemistry, Physiology and Health Effects, pp. 417-430 [D Kritchevsky, C Bonfield and JW Anderson, editors]. New York: Plenum.

Hill MJ, Morson BC \& Bussey HJR (1978) Etiology of the adenoma-carcinoma sequence. Lancet i, 245-247.

Jensen OM (1984) Different age and sex relationship for cancer of subsites of the large bowel. British Journal of Cancer 50, $825-829$.

Jensen OM (1989) Dietary fibre, carbohydrate and cancer: epidemiological evidence. In Diet and the Aetiology of Cancer, pp. 21-30 [AB Miller, editor]. Heidelberg, Germany: Springer Verlag.

Little J \& Sharp L (2002) Colorectal neoplasia and genetic polymorphisms associated with folate metabolism. European Journal of Cancer Prevention 11, 105-110.

Morson BC (1974) The polyp-cancer sequence in the large bowel. Proceedings of the Royal Society of Medicine 67, 4551-4557.

Morson BC, Bussey HJR, Day DW \& Hill MJ (1983) Adenomas of the large bowel. Cancer Surveys 2, 451-478.

Olschwang S (1999) Germline mutation and genome instability. European Journal of Cancer Prevention 8, Suppl. 1, s33-s38.

Stephen AM, Haddad AC \& Phillips S (1983) Passage of carbohydrate into the colon; direct measurements in humans. Gastroenterology 85, 589-595. 